\title{
GIS BASED MULTI-CRITERIA DECISION ANALYSIS FOR INDUSTRIAL SITE SELECTION: THE STATE OF THE ART
}

\author{
Aleksandar Rikalović* \\ Faculty of Technical Sciences, Novi Sad, Serbia \\ Ilija Cocić \\ Faculty of Technical Sciences, Novi Sad, Serbia
}

Industrial site selection is one of the basic vital decisions in the start-up process, expansion or relocation of businesses of all kinds. Starting from the meeting criteria defined in the business strategy, site selection process begins as recognition of existing or projected need to meet new or growing market. Recognition of the need of new industrial location initiate a series of activities directed for looking geographical area and specific location. Conquer new territories for business starts with collecting geopolitical data, where location is a part of it. The selection of an industrial site involves a complex array of critical factors involving economic, social, technical, environmental, political issues, etc. It is obvious that many factors must be involved in the decision-making process, which makes the problem challenging choice in the selection of appropriate tools to enable concentration data, information and analysis. New trends in information technologies put geo-information technology in the centre of events in industrial locations science. Geographic Information Systems (GIS) provides functionality to capture, store, query, and analyse geographic information, but that is not enough for multi criteria analysis and decision making. Recent development in GIS leads to dramatic improvement in multi-criteria decision analysis (MCDA) and decision making. This paper presents the state of the art in GIS based multi-criteria decision analysis for industrial site selection.

Key words: Geographic Information Systems (GIS), Industrial Site Selection, Multi-Criteria Decision Analysis (MCDA), Spatial Decision Support Systems (SDSS)

\section{INTRODUCTION}

Industrial site selection is one of the key vital decisions in the process of starting, expanding or changing the location of industrial systems of all kinds. Structural complexity of the industrial system and the relationship with the environment, changes in market demand, the characteristics of the production programs, economic conditions, working conditions, environmental and other impacts, determine the location of new industrial systems, while changes in production programs, the characteristics of the work process, the frequency of technological changes and the disorder effects requires adjustment of the existing location of industrial systems (Zelenovic, 2003). One of the most important and far reaching decisions faced by operations managers is deciding where to locate new industrial facilities. This is a strategic decision involving irreversible allocation of the firm's capital, and often has a crucial impact on key measures of the firm's supply chain performance such as lead time, inventory, responsiveness to demand variability, flexibility, and quality (Bhatnagar \& Sohal, 2005).

One of the main goals of industrial site selection is finding the most appropriate site with desired conditions defined by the selection criteria. The industrial site selection, seeks to optimize the number of goals in determining the suitability of a specific location for a defined industrial system. Such optimization often involves numerous decision factors, which are frequently contradicting, and the process often involves a number of possible sites each has advantages and limitations. Industrial site selection process means complex multi-criteria analysis which includes a complex array of factors involving economic, social, technical, environmental and political issues that may result in conflicting objectives (Williams and Massa, 1983). Many factors must be involved in the decisionmaking process, which makes the problem challenging choice in the selection of appropriate tools to enable data collection storage and analysis. 
Industrial decision making is based on numerous data concerning the problem. It has been estimated that $80 \%$ of data used by managers and decision makers are geographical (spatial) in nature (Worral, 1991). Decision problems that involve geographical data are referred to as geographical or spatial decision problems (Malczewski, 2004). Geography is a critical factor, contributing to an industry's competitive advantage. Geographic information systems (GIS) are powerful tool designed for managing spatial data and spatial analysis which provides functionality to capture, store, query, analyse, display and output geographic information (Bolstad, 2002). As such they have big influence in spatial decision making process. Recent development in field of decision making leads to dramatic improvements in the capabilities of GIS in location analysis. These development are reviewed through analysis of attribute data especially procedures for Multi-criteria and Multi-objective location analysis in GIS (Malczewski, 1999; Eastman, 2006; Rinner and. Voss, 2013).

This paper is organized as follows. In Section 2, we summarize the literature overview in the industrial site selection field, pointing out the characteristics of selection process and critical factors. In Section 3 we present the state of the art in GIS based multi-criteria analysis for industrial site selection. Section 4 derives some conclusions and directions for future research.

\section{BACKGROUND}

In the past, industrial site selection was based almost purely on economic and technical criteria.

Nowadays, in the post-industrial society and knowledge-based society, people become the most important resource (Florida, 2002; Nordstrom and Ridderstrale, 2002). Today, a higher degree of sophistication is expected. Selection criteria must also satisfy a number of social and environmental requirements, which are enforced by legislations and government regulations (Williams and Massa, 1983; Keeney, 1980). Proximity to universities and scientific institutions, number of innovation per citizen can be one of the key factors for decision makers. All so risk management is an indispensable analysis in site selection process. Managing the risks involved in selecting a new industrial location is one of the most critical factors in determining the ultimate success or failure of a business. To keep risks at a minimum, investors should first be familiar with the stages of the site selection process and what are the key risks that need to be considered and managed during each of these stages.

Collection of information allows the generation of a potential industrial sites that can be grouped, while the use of selection criteria, through several iterations, gradually narrowing to a choice (Figure 1). In such way, of the total number of available sites, the customer is aware of just a certain number of them. Of these, only a certain number of locations meet the selection criteria of the decision maker. By collecting information on these locations, it remains just making a group of locations that are included in the shortlist. Out of this group, based on the criteria used by the decision maker (investor) chooses one location (Kotler et al., 1993).

Site selection problems are characterized by their multi-objectives and numerous stakeholders, some of the issues that add to the complexity of the site selection process include existence of (Williams and Massa 1983, Keeney 1980):

- Large number of possible sites - in the region of interest, there are usually many potential sites that could be chosen for the facility;

- Multiple - contradicting objectives - for instance a firm is locating the manufacturing plant in a third world country to take advantage of low labour cost, in the same time company must estimate whether the poor infrastructure or the non-availability of skilled labour may decrease it's capability to compete with competition;

- Intangible objectives that are difficult to quantify there are many factors that are very difficult to quantify like is quality of education system in the country;

- Diversity of interest groups - Frequently, owners/ investors decisions are influenced by several public groups in addition to their own organization;

- Impact Assessment - Placing the value on the impact of each objective could be problematic. It is not enough to state that there would/ wouldn't be some impact. A value (number) is needed to support the comparison process;

- Impact timing - The impact of interest in most sitting studies may not occur all at the same time and may/ may not continue over the lifetime of the project;

- Impact uncertainties - It is practically impossible to accurately forecast all possible impacts of all factors affecting the site selection;

- Delays - Licensing and construction are examples of common unpredictable delays that may signifi- 
cantly impact the economic viability of the project;

- Operation reliability - Uncontrollable and unpredictable natural phenomena such as storms, floods, quacks and similar phenomena can influence site suitability;

- Value trade-offs - Decisions regarding value tradeoffs especially among multiple contradicting objectives are challenges for the decision maker;

- Equity - Determining equity and fairness among all interest groups could be a difficult task that involves complex value judgments;

- Stakeholders' risk attitudes - Determination and compilation of the stakeholders' risk attitudes (utility functions) is important to the proper site selection;
- Uncertainties in government decisions - The actions of the state governments can have a great influence on the relative desirability over time of different locations for a proposed facility.

According to Zelenovic the process of site selection includes (Zelenovic, 2003):

- Establishing a set of influential factors relevant to site selection,

- Predicting and evaluating the intensity and direction of their effects in time and conditions.

- Evaluation of possible variants of solutions and selection of optimal variant.

Application of the procedure has equal importance in selection of macro and micro location (Figure 2). The term macro and micro location is explained in the Figure 2.

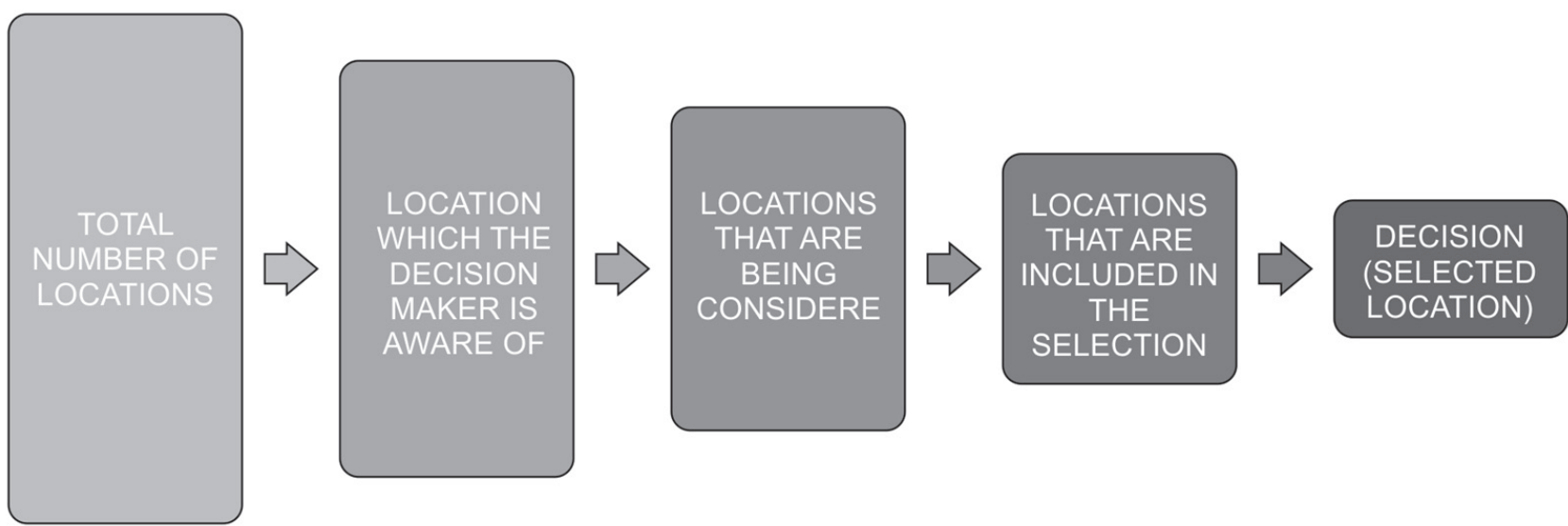

Figure 1: Potential industrial sites

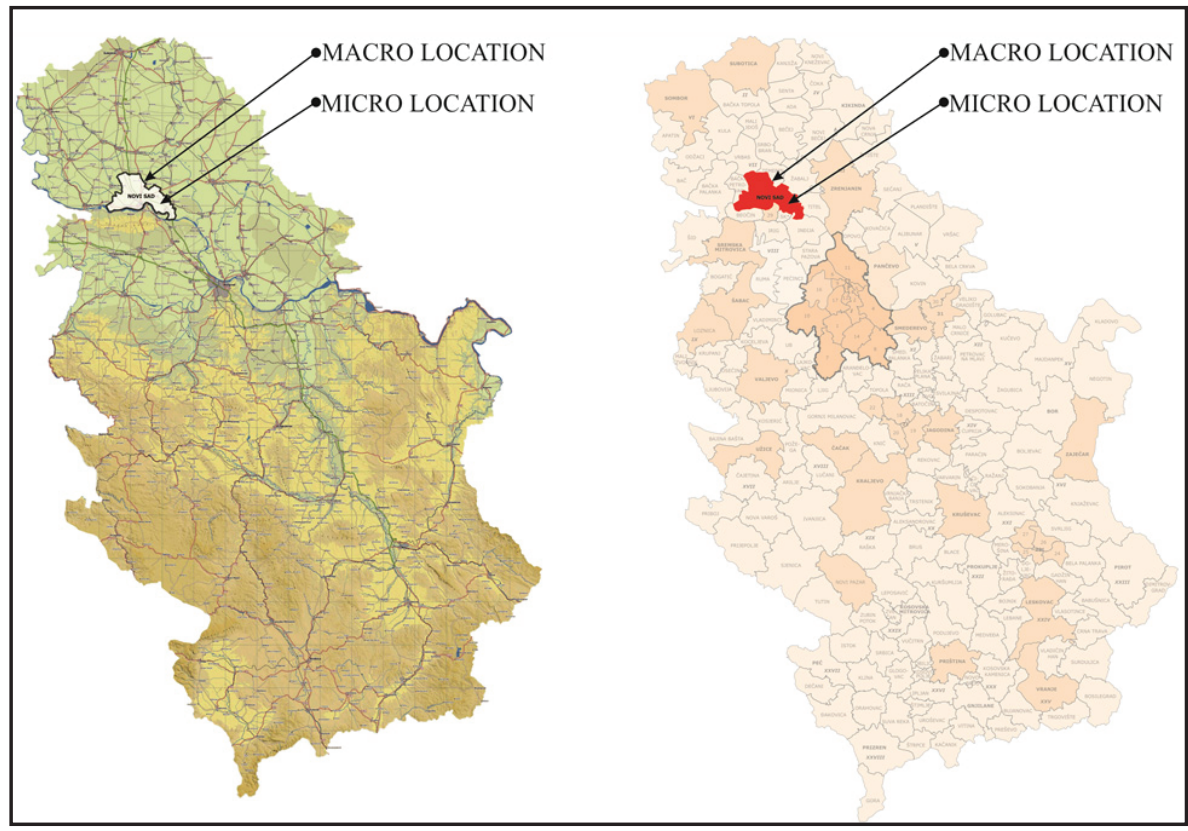

Figure 2: Review of Macro and Micro location in site selection process 
- Macro Location - the geographical area, which can meet the basic requirements for construction and development of industry with minimal operating costs;

- Micro Location - $s$ the specific place in the macro location that meets technical, infrastructural and working process requirements The basic steps in the process of site selection at international and national field are given by Figure 3:

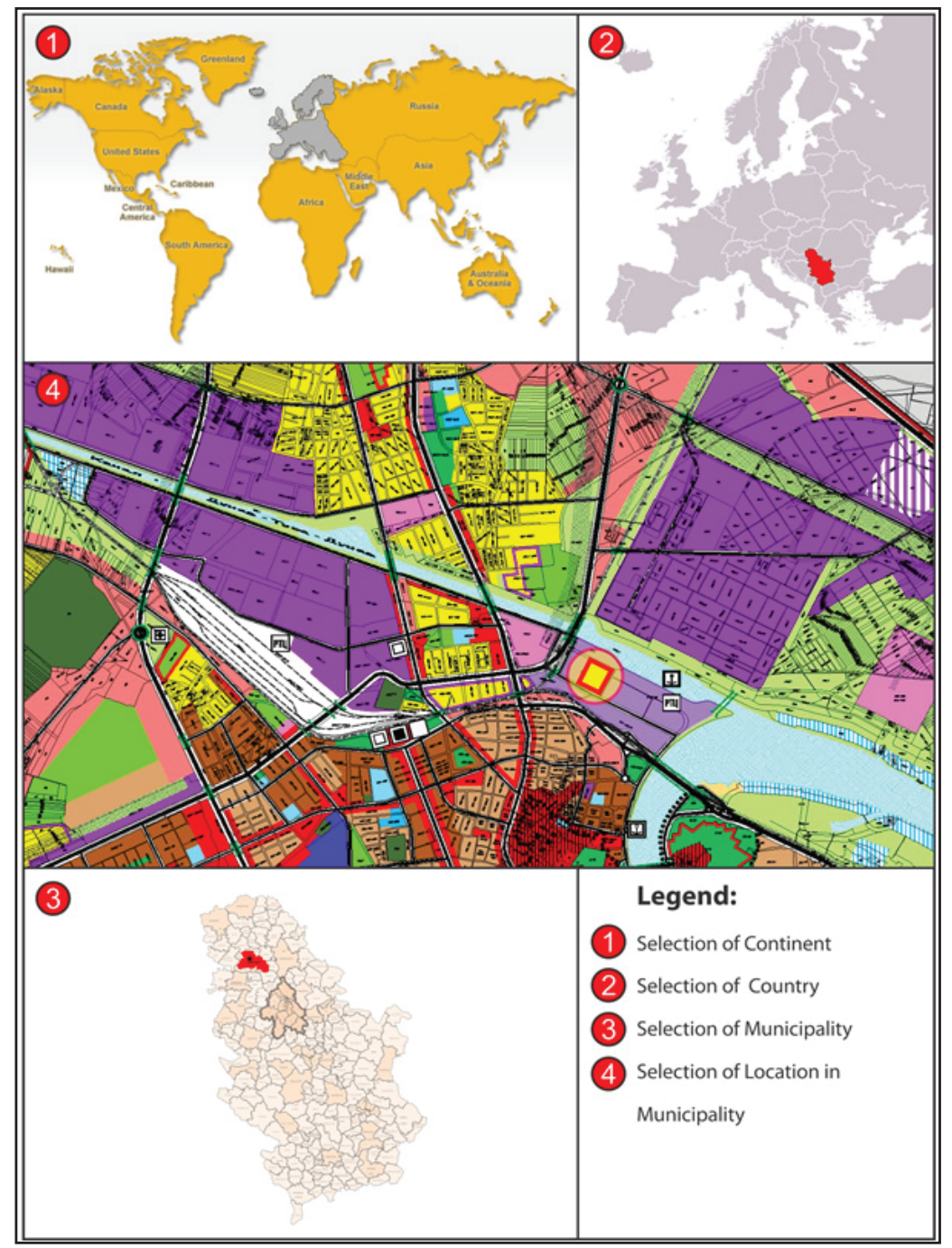

Figure 3: Basic steps in site selection process

The industrial site selection process means complex multi-criteria analysis which includes a complex array of factors involving economic, social, technical, environmental and political issues. It is obvious that many factors must be involved in the decision-making process, which makes the problem challenging choice in the selection of appropriate tools to enable concentration data, information and knowledge. One of the first step in the industrial site analysis should be overview and classification of factors influencing the decision of location. Short review of factors is presented in Table 1 (Badri, 2007). Some of these factors can be measure with quantitative methods and some of them with qualitative. Quantitative meth- ods place greatest reliance on representing values numerically. Numerical data, of many types, are useful in thinking about long-term investments (costs of labour, cost of electrical power, cost of industrial land, proximity to the highway etc.). Qualitative methods can be very useful in the research of those factors which are difficult to quantify like is climate, education system, availability of labour, etc. Many factors must be involved in the decision-making process, which makes the problem challenging choice in the selection of appropriate tools to enable data collection, data storage, data analysis, data normalization, data fusion and knowledge. Identifying the optimal location for industry is a spatial problem 
that requires comparison of the attributes of different places, and finding the best fit location in a place that has the most suitable combination of desired attributes. A number of tools have been used to select proper sites. These tools include expert systems, geographic information systems and multi-criteria decision-making methods.

For example, intelligent approach for industrial site selection based on GIS, expert system and Analytic Hierarchy Process (AHP) method (Figure 4) (Eldin \& Sui, 2003), divides the process into two phases: screening and evaluation phases.

Table 1: Review of industrial location factors

\begin{tabular}{|l|l||}
\hline Factors & Explanation of Factor \\
\hline Transportation & $\begin{array}{l}\text { Pipeline facilities; Airway facilities; Highway facilities; Railroad facilities; Trucking services; Water- } \\
\text { way transportation; Shipping cost of raw material; Cost of finished goods transportation; Availabil- } \\
\text { ity of postal services; Warehousing and storage facilities; Availability of wholesale outlets. }\end{array}$ \\
\hline Labour & $\begin{array}{l}\text { Low cost labour; Attitude of workers; Managerial labour; Skilled labour; Wage rates; } \\
\text { Unskilled labour; Unions; Educational level of labour; Dependability of labour; Avail- } \\
\text { ability of male labour;. Availability of female labour; Cost of living; Worker stability. }\end{array}$ \\
\hline Raw Materials & $\begin{array}{l}\text { Proximity to supplies; Availability of raw materials; Nearness to component parts; Availability } \\
\text { of storage facilities for raw materials and components; Location of suppliers; Freight cost. }\end{array}$ \\
\hline Markets & $\begin{array}{l}\text { Existing consumer market; Existing producer market; Potential consumer market; Anticipation } \\
\text { of growth of markets; Shipping costs to market areas; Marketing services; Suitable competitive } \\
\text { position; Income trends; Population trends; Consumer characteristics; Location of competitors; } \\
\text { Future expansion opportunities; Size of market; Nearness to related industries. }\end{array}$ \\
\hline Industrial Site & $\begin{array}{l}\text { Accessibility of construction land; Cost of industrial land; Developed industrial park; } \\
\text { Space for future expansion; Insurance rates; Availability of lending institutions; Close- } \\
\text { ness to other industries;. Attitude of financing agents. }\end{array}$ \\
\hline Utilities & $\begin{array}{l}\text { Attitude of utility agents; Water supply, cost and quality; Disposable facilities of industrial } \\
\text { waste; Availability of fuels; Cost of fuels; Availability of electric power; Cost of electric power; } \\
\text { Availability of gas; Adequacy of sewage facilities. }\end{array}$ \\
\hline Government At- \\
titude & $\begin{array}{l}\text { Building ordinances; Zoning codes; Compensation laws; Insurance laws; Safety } \\
\text { inspections; Nuisance and stream pollution laws. }\end{array}$ \\
\hline Tax Structure & Taxassessment basis; Industrial property tax rates; State corporate tax structure; Tax free operations. \\
\hline Climate & $\begin{array}{l}\text { Amount snow fall; Rain fall; Living conditions; Relative humidity; Monthly average } \\
\text { temperature; Air pollution. }\end{array}$ \\
\hline
\end{tabular}

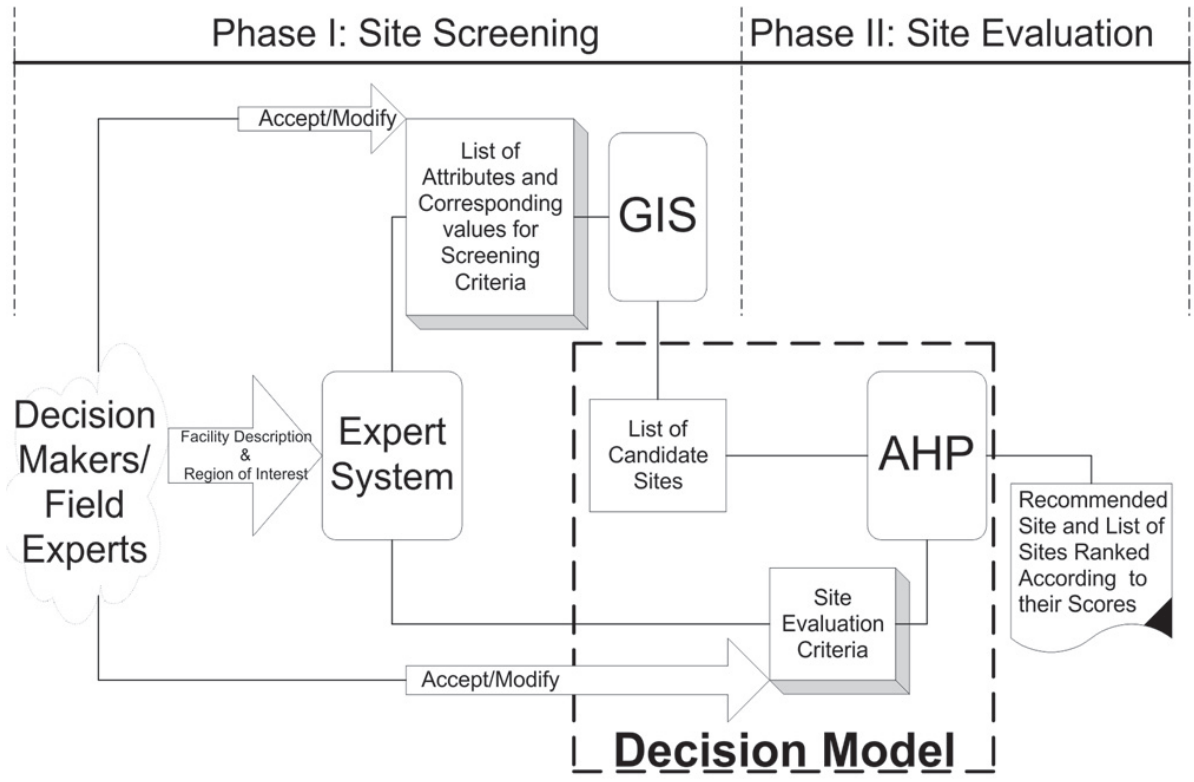

Figure 4: Architecture of the Intelligent GIS Approach 
In the screening phase ES recommends suitability criteria and GIS screens all candidate sites located in the region of interest. In evaluation phase AHP is used outside of GIS to identify the most appropriate site by comparing alternative sites on the basis of the non-spatial attributes.

\section{GIS AND MULTI-CRITERIA DECISION ANALYSIS FOR INDUSTRIAL SITE SELECTION}

\section{The Roll of Geographic Information Systems in Industrial Selection}

Geographic information systems are group of procedures that provide data input, storage, mapping and spatial analysis to support the decision-making activities of the organization (Grimshaw and Bringing, 1996). Since, geographical information systems provide the capability to enter, edit, retrieve, analyse, map, and visualize spatial data it is not surprising to see that spatial data is marketed primarily in a GIS format.

GIS has the ability to stores geographic data (spatial data) and attribute (descriptive) data. Spatial data represents features with known location on the earth, while attribute data is non-graphic information linked to the geographical features (spatial data), which describes features. There are two methods (or data models) used to structure spatial data in GIS: raster data model and the vector data model (Figure 5). The raster model is most effective for modelling and is commonly used with image processing; the vector model is more widely used, provides higher accuracy and better cartographic capabilities.

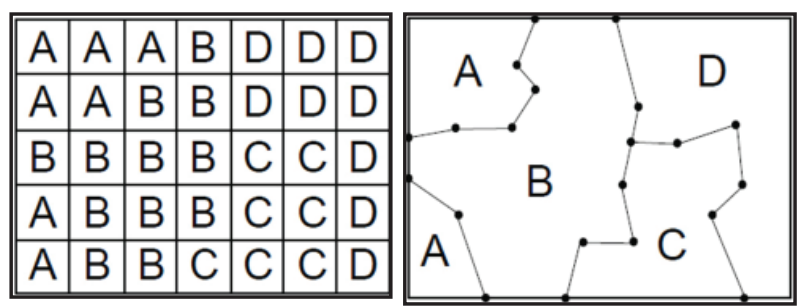

Figure 5: Raster and vector data model

GIS techniques \& procedures have an important role in analysing industrial site selection problems in a form of spatial data analysis, especially in generating alternatives (screening phase) (Rikalovic et al., 2014). Spatial data analysis is concerned with that branch of data analysis where the geographical referencing of objects contains important information. A definition of spatial analysis (of which spatial data analysis is one element) is that it represents a collection of techniques and models that explicitly use the spatial referencing of each data case. Spatial analysis needs to make assumptions about or draw on data describing spatial relationships or spatial interactions between cases. The results of any analysis will not be the same under rearrangements of the spatial distribution of values or reconfiguration of the spatial structure (Goodchild, 1992). The most commonly used spatial analysis in GIS is (Figure 6):

- Analysis of attributive (tabular) data,

- Overlapping layers (i.e. query of spatial data)

- Analysis of the distance, ("Buffering")

- Network analysis and

- Nonparametric techniques.

Analysis of the buffer zone is used when it's needed to locate all locations that are in a zone (a distance) of the observed object. In the example given in Figure 6 we can see buffer analysis for production locating. In presented example we assume that the location must be in the industrial areas and that the highway may be the most distant $1 \mathrm{~km}$ from the potential location. Often such a request is performed excluding all locations that are further than $1 \mathrm{~km}$ from the highway, using common ArcGIS function called "Buffering". Analysis of attribute data of one thematic layer can be performed: as SQL query against a table with attribute data; using different arithmetic operations (addition, subtraction, multiplication, etc.), logarithmic functions, trigonometric functions, and so on; application of some nonparametric techniques like multi-criteria methods and methods based on artificial intelligence. However, GIS has several limitations in spatial decision making which are due in great part to the lack of sophisticated analytical and spatial modelling tools. The solution generally adopted to enhance the GIS in spatial decision making consists in coupling it with other computing and operational research tools. Among these tools, the multi-criteria decision analysis is naturally the most appropriate one. Combining multi-criteria analysis and GIS for overcoming shortcomings of one tool by the strength of another to help decision making process.

\section{GIS based Multi-Criteria Decision Analysis for Industrial Site Selection}

Many factors must be involved in industrial site selection process, which makes the problem challenging choice in the selection of appropriate spatial tools to enable concentration data, information and knowledge. Spatial decision problems typically involve a 
large set of feasible alternatives \& multiple evaluation criteria (Chakhar and Mousseau, 2008). New trends in information technologies put GIS in the centre of location science and spatial decision support.

Industrial site selection, usually involve not only technical requirements, but also economic, social, environmental and political factors (Figure 7). Solutions for such challenges frequently involve highly com- plex spatial decision making processes that require simultaneous use of several decision support tools such as geographic information systems and multicriteria decision making techniques. Integration of the capabilities of these tools is crucial to the feasibility of reaching a final solution. Therefore, developing efficient integration strategies became a high priority to many researchers (Eldrandaly et al., 2005).

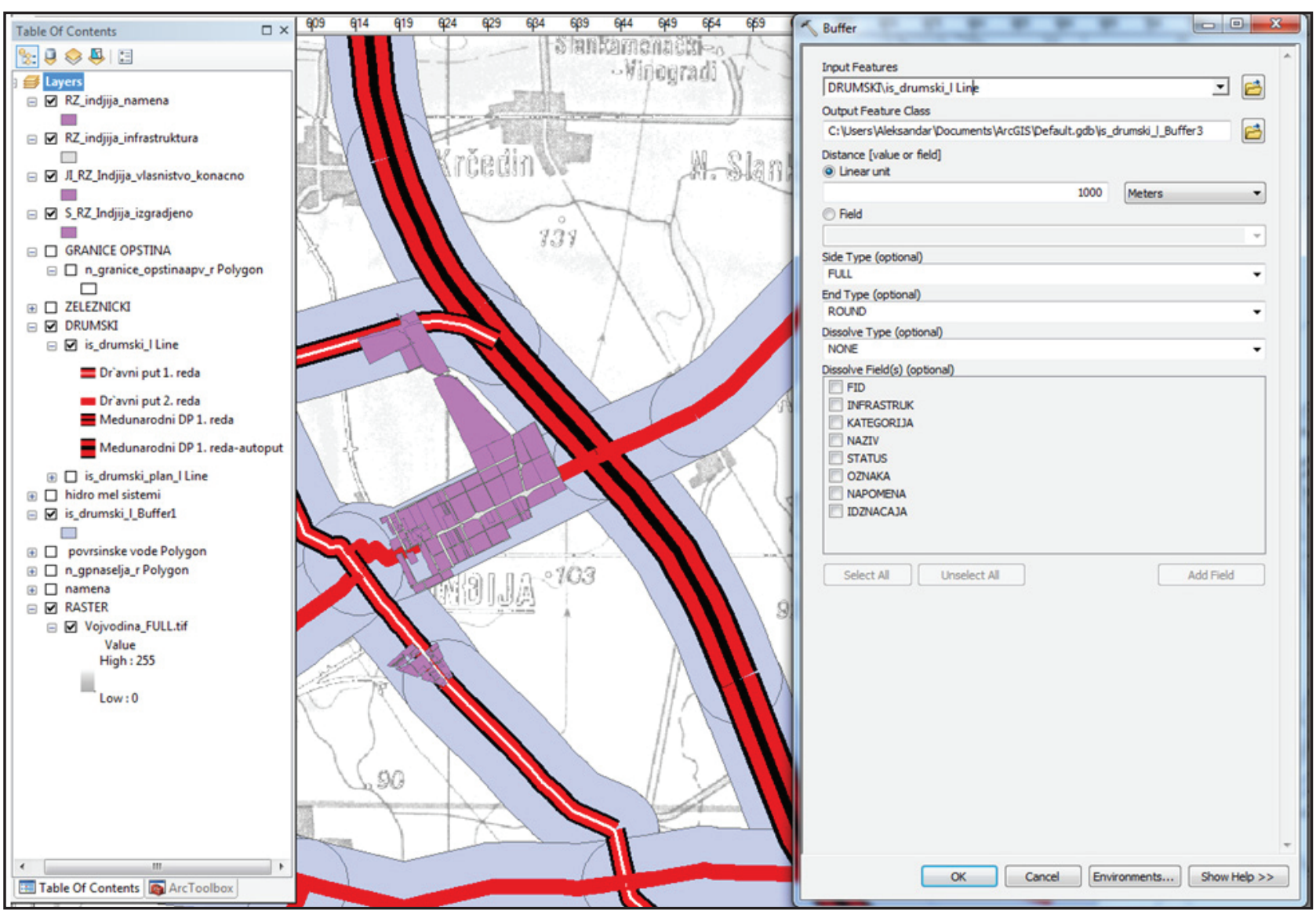

Figure 6: Raster and vector data model
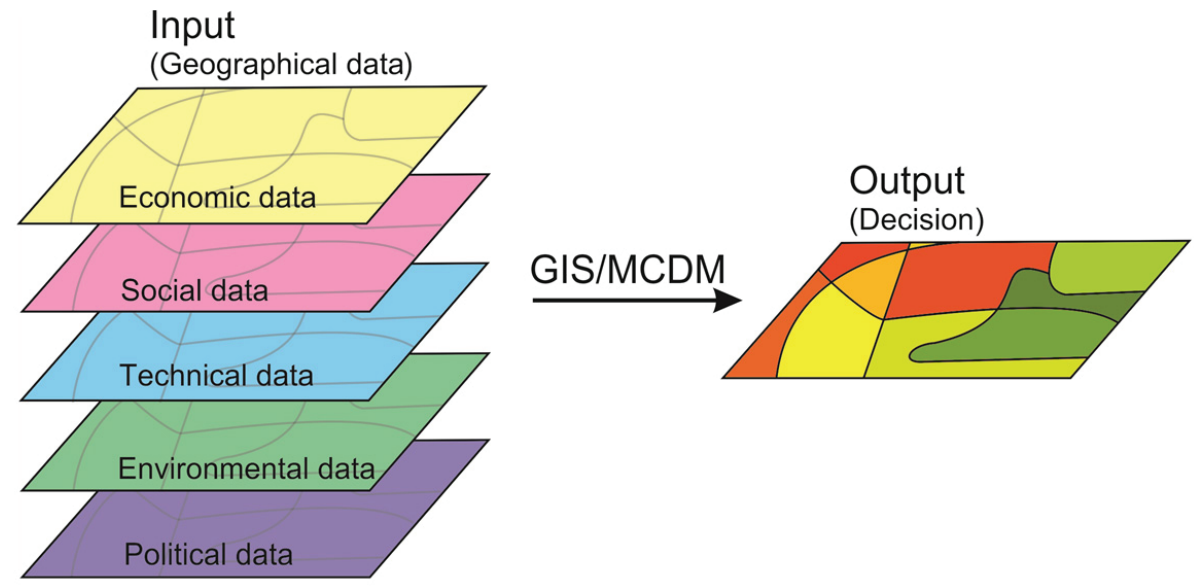

Figure 7: Spatial multi-criteria analysis 
Multi-criteria decision making problems can be classified on the basis of the major components of multi-criteria decision analysis: Multi-Objective Decision Analysis (MODA) versus MultiAttribute Decision Analysis (MADA), individual versus group decision-maker problems, and decision under certainty versus decision under uncertainty. The distinction between MODA and MADA is based on the classification of evaluation criteria into attributes and objectives (Malczewski, 2004). Multi-attribute techniques are discrete methods because they assume that the number of alternatives is explicit. The multi-objective methods are mathematical programming model-oriented, where the alternatives, identified by solving a multi-objective mathematical programming problem, must be generated. According to Kenney [16], two major approaches include the alternative-focus approach, which focuses on generating decision alternatives, and the value-focus approach, which uses the values (evaluation criteria) as a fundamental element of the decision analysis (Kenney, 1992).

Recent developments in the field of decision making have led to dramatic improvements in the capabilities of GIS in industrial location analysis. These development are reviewed through analysis of attribute data especially procedures for Multi-criteria location analysis in GIS. Over the last decade, a number of multi-attribute (or multi-criteria) evaluation methods have been introduced in the GIS environment. The most commonly used analysis are: Weighted Linear Combination (WLC) and Ordered Weighted Averaging (OWA) (Malczewski, 2000; Rinner and Malczewski, 2002; Eastman, 2006; Drobne et al., 2009; Rinner and Voss, 2013).

Weighted linear combination (WLC), or simple additive weighting, is based on the concept of a weighted average in which continuous criteria are standardized to a common numeric range, and then combined by means of a weighted average. The decision maker assigns the weights of relative importance directly to each attribute map layer. The total score for each alternative is obtained by multiplying the importance weight assigned to each attribute by the scaled value given for that attribute to the alternative and then summing the products over all attributes. The scores are calculated for all of the alternatives and that with the highest overall score is chosen (Malczewski, 2000; Drobne et al., 2009).
With the weighted linear combination, factors are combined by applying a weight to each followed by a summation of the results to yield a suitability map (Figure 8):

$S=\sum w_{i} x_{i}$

Where $S$ is suitability, $w_{i}$ is weight of factor $i$, and $x_{i}$ is the criterion score of factor $i$. In cases, where Boolean constraints also apply, the procedure can be modified by multiplying the suitability calculated from the factors by the product of the constraints:

$S=\sum w_{i} x_{i} \cdot \prod c_{j}$

Ordered Weighted Averaging (OWA) uses a class of multi-criteria operators (Yager, 1988) and involves two sets of weights: criterion, or importance weights and order weights (Boroushaki and. Malczewski, 2008).

A criterion weight is assigned to a given criterion or attribute for all locations in a study area to indicate its relative importance, according to the decision-maker's preferences, in the set of criteria under consideration. The order weights are associated with the criterion values on a location-by-location basis. They are assigned to a location's attribute values in decreasing order with no consideration of the attribute source of each value. The re-ordering procedure involves associating an order weight with a particular ordered position of the weighted attribute values. The first order weight is assigned to the highest weighted attribute values for each location, the second order weight to the second highest values, and so on (Drobne et al., 2009).

Geographic information systems have been used to identify suitable areas for industry using multicriteria evaluation method called Boolean logic for producing suitability maps (Reisi et al., 2011). The Boolean method evaluates the study area, using a grading scale $[0,1]$ where 0 denotes sites totally unsuitable for industry while 1 shows sites suitable for industries. In recent industrial location research Simple Additive Weighting (SAW) method was presented under the GIS environment (Charungthanakij and Sarapirome, 2010). Applying SAW method as the decision rule, the sum of product class scores within factors and their weights indicates spatial ranking of land suitability for industrial location.

The industrial location problem requires complex knowledge management and analysis. The need of an appropriate support to human decision makers is due to 
four kinds of limits: cognitive, economic, time and competitive demands (Reisi et al., 2011). Management of uncertainty is an important issue in the design of decision support system since data maybe indefinite, inaccurate and ambiguous (Puškarić et al., 2013).

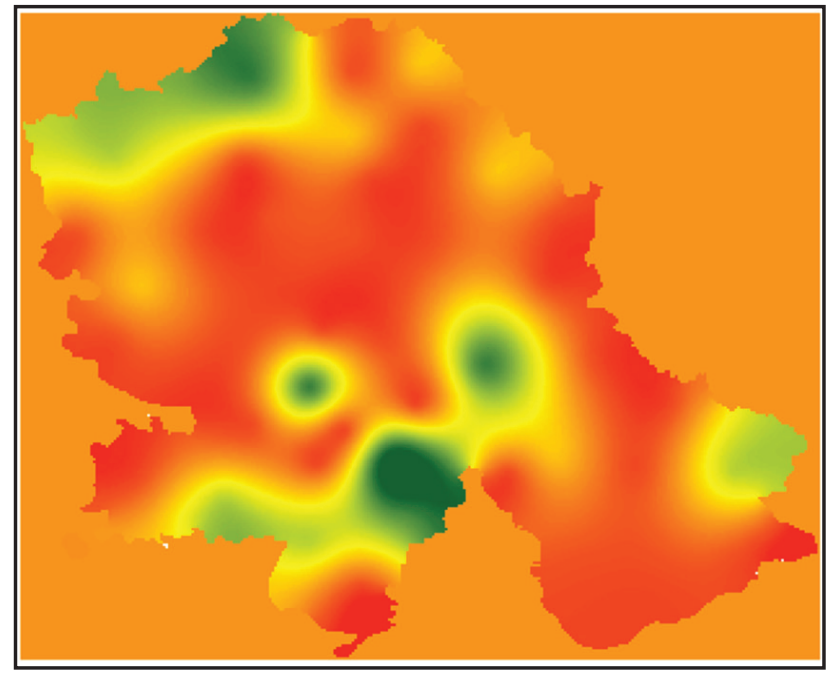

Figure 8: Suitability map: a) Raster suitability map; b) Vector suitability map
Unfortunately, there is not enough scientific research on industrial site selection filed that would cover all the important aspects of decision making on a comprehensive way.

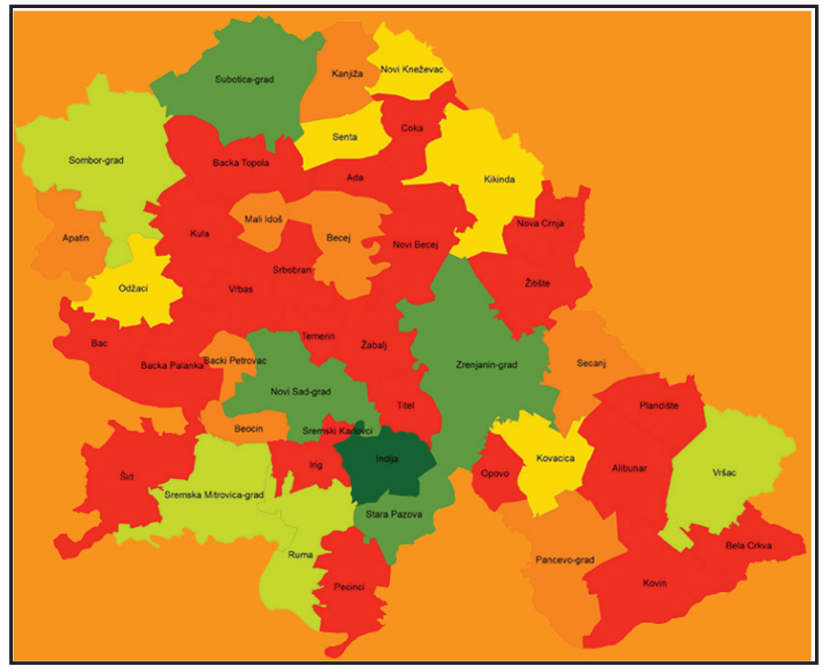

\section{CONCLUSION}

This paper presents the state of the art in GIS based multi-criteria decision analysis for industrial site selection. We present literature overview in industrial site selection filed, pointing out the characteristics of selection process and complex multi-criteria analysis which includes a complex array of factors. We analysed the roll of geographic information systems and multi-criteria decision analysis in industrial site selection. Special emphasis is given to a spatial analysis and GIS based multi-criteria decision analysis.

Spatial analysis is presented as GIS techniques \& procedures that have an important role in analysing industrial site selection problems especially in generating alternatives (screening phase). We presented the most commonly used spatial analysis in GIS and provided examples of applications in the industrial site selection field. As well we presented several limitations in GIS which are due in great part to the lack of sophisticated analytical and spatial modelling tools. As solution we combining multi-criteria analysis and GIS for overcoming shortcomings of one tool by the strength of another to help decision making process.

We classified multi-criteria decision making problems as: multi-objective decision analysis versus multi-attribute secision analysis, individual versus group decision-maker problems, and decision under certainty versus decision under uncertainty. We presented the most commonly used MCDA techniques under the GIS environment, and provide an overview of the application of GIS-MCDA in industrial site selection filed.

Previous research is very welcome but not sufficient in industrial site selection. Need for new research is necessary to allow quantitative and qualitative analysis under uncertainties on comprehensive way.

\section{REFERENCES}

1) Badri M. A. (2007), "Dimensions of Industrial Location Factors: Review and Exploration", Jornal of Business and public affairs, Volume 1, Issue 2. pp. 1-26.

2) Bhatnagar, R., \& Sohal, A. S. (2005), "Supply chain competitiveness: measuring the impact of location factors, uncertainty and manufacturing practices", Technovation, Vol: 25, No:5, pp. 443-456.

3) [Bolstad, P. (2002), GIS Fundamentals, Eider Press, Minnesota, USA.

4) Boroushaki S. and Malczewski J. (2008), „Implementing an extension of the analytical hierarchy process using Ordered Weighted Averaging Operators with Fuzzy Quantifiers in ArcGIS," Computers \& Geosciences. Vol. 34 No. 4, pp. 399-410. 
5) Chakhar S. and Mousseau V. (2008),"GISbased multicriteria spatial modeling generic framework", International Journal of Geographical Information Science, Vol. 22, No. 11-12, pp.1159-1196.

6) Charungthanakij S. and Sarapirome S. (2010), "Land suitability assessment for industrial location development using MCDA." In The 31st Asian Conference on Remote Sensing, pp. 1-5.

7) Drobne, Samo, Lisec, Anka, (2009), „Multiattribute Decision Analysis in GIS: Weighted Linear Combination and Ordered Weighted Averaging“, Informatica 33, pp. 459-474.

8) Eastman J. R. (2006), Idrisi Andes - Tutorial, Clark Labs., Clark University, Worcester, MA.

9) Eldin, N., \& Sui, D. (2003), „A COM-based Spatial Decision Support System for Industrial Site Selection“, Journal of Geographic Information and Decision Analysis, Vol. 7, No. 2, pp. $72-92$.

10) Eldrandaly K., Eldin N., Sui D., Shouman M., \& Nawara, G. (2005)," Integrating GIS and MCDM Using COM Technology", The International Arab Journal of Information Technology, Vol. 2, No.2, pp. 162-167.

11) Florida R. (2002), The Rise of the Creative Class. The Washington Monthly, pp. 15-25.

12) Grimshaw D. J. (1996), Bringing Geographical Information Systems into Business (2nd edition), Cambridge, Geolnformation International.

13) Goodchild, M., Haining, R., and Wise, S. (1992), "Integrating GIS and spatial data analysis:problems and possibilities", International Journal of Geographical Information Systems, Vol. 6, pp. 407-423.

14) Keeney R.L (1992), Value-focused thinking: a path to creative decision making, University Press, Cambridge.

15) Keeney R.L.(1980), Siting Energy Facilities, Academic Press, New York.

16) Kotler P.J., Haider D.H., Rein, I. (1993), Marketing places: Attracting investment, industry and tourism to cities, states and nations, Free Press, New York.

17) Nordstrom K.A., Ridderstrale, J. (2002), Funky business: Talent makes capital dance, Bookhouse Publishing, London.

18) [Malczewski J. (1999), GIS and Multicriteria Decision Analysis, John Wiley \& Sons, New York.
19) Malczewski J. (2000), „In the Use of Weighted Linear Combination Method in GIS: Common and Best Practice Approaches", Transactions in GIS, Vol. 4, No.1, pp.5-22.

20) Malczewski J. (2004), "GIS-based land-use suitability analysis: a critical overview," Progress in Planning, Vol.62, No.1, pp. 3-65.

21) Puškarić, H., Tadić, D., Misita, M., Stefanović, M., Milanović, D. (2013), „Evaluation of quality goals at the process level in an uncertain environment", Journal of Applied Engineering, No. 1, Vol. 11, pp. 31-38

22) Rinner, C. and Malczewski, J. (2002), „Webenabled spatial decision analysis using ordered weighted averaging (OWA)“, Journal of Geographical Systems Vol. 4, No.4, pp. 385-403.

23) Rinner C., Voss S. (2013), "MCDA4ArcMap An Open-Source Multi-Criteria Decision Analysis and Geovisualization Tool for ArcGIS 10", Feature Article, Cartouche, Newsletter of the Canadian Cartographic Association, Number 86, Winter/Spring, pp.12-13.

24) Rikalovic A., Ćosić I., Lazarević Dj. (2014), "GIS Based Multi-Criteria Analysis for Industrial Site Selection", 24th DAAAM International Symposium on Intelligent Manufacturing and Automation, Procedia Engineering 69, pp.1054 1063.

25) Reisi M., Aye L., Soffianian A., (2011), "Industrial site selection by GIS in Isfahan," 19th Iran International Conference on Geoinformatics.

26) Williams, E.A., Massa, A.K. (1983), Siting of Major Facilities: A Practical Approach, McGraw- Hill, New York.

27) Worral L. (1991), Spatial Analysis and Spatial Policy using Geographic Information Systems, Belhaven Press, London

28) Yager R. R. (1988), „,On ordered weighted averaging aggregation operators in multi-criteria decision making "IEEE Transactions on Systems, Man and Cybernetics, Vol.18, No.1, pp. 183-190.

29) Zelenovic D. (2003), Production systems design, Faculty of Technical Sciences, Novi Sad.

Paper sent to revision: 18.11.2013.

Paper ready for publication: 09.09.2014. 